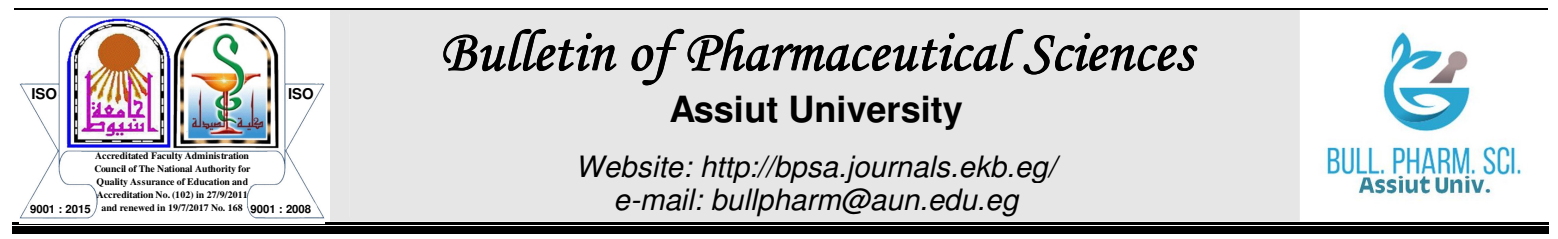

\title{
KETOROLAC TROMETHAMINE LOADED NANOPARTICLES FOR OCULAR DELIVERY: FORMULATION, IN-VITRO AND EX-VIVO EVALUATION
}

\author{
Raafat Elsayed Osman*, Gihan Fetih and Fawzia Habib \\ Department of Pharmaceutics, Faculty of Pharmacy, Assiut University, Assiut, Egypt
}

\begin{abstract}
The objective of the current study was preparation of ketorolac tromethamine $(K T)$ loaded nanoparticles (NPS) based on two polymers (Eudragit RL 100 and Gelatin) for ocular applications providing a controlled drug release to improve $K T$ bioavailability. Nanoprecipitation technique was used to prepare eudragit RL 100 NPs while gelatin NPs were prepared using two-step desolvation technique. The formulations were evaluated in terms of particle size, zeta potential, polydispersibity index (PDI) and physicochemical characterizations (DSC, FTIR, X-ray diffraction). Drug entrapment, in-vitro release, ex-vivo permeation, histological examination and stability at different conditions were also examined. The optimized parameters have been determined and were suitable for possible ocular application. NPs showed sustained drug release in-vitro and higher permeation as compared to that of Acular ${ }^{\circledR}$ solution. These preliminary results indicated that KT loaded NPs are effective in sustaining drug release and could be used for improving ocular delivery of KT.
\end{abstract}

\section{INTRODUCTION}

Non-steroidal anti-inflamatory drugs (NSAIDs) have demonstrated to be a safe and successful option in contrast to corticosteroids in the topical administration of ocular inflammations as pre and post operatory treatment. As pre-operatory treatment, topically applied NSAIDs are normally utilized for the counter active action of ocular inflammations and cystoid macular edema because of injury caused by cataract surgery and the support of mydriasis during cataract surgery ${ }^{1}$.

Ketorolac tromethamie (KT) is one of the NSAID belonging to the family of heterocyclic acetic acid derivatives ${ }^{2}$. It prevents postoperative eye inflammation, reduces conjunctivitis connected with no changes of corneal opacity. Ketorolac tromethamine is an unselective cyclooxygenase (COX) inhibitor. It is administered as tromethamine salt, orally, intramuscularly, intravenously and as a local ophthalmic solution. Ketorolac tromethamie is accessible as a local ophthalmic solution (0.4$0.5 \% \mathrm{w} / \mathrm{v})$, tablets $(10 \mathrm{mg})$ and solution for injection $\quad\left(15-30 \quad \mathrm{mg} \cdot \mathrm{ml}^{-1}\right)^{3}$. Superficial treatment is not efficacious due to affectionate mechanisms of the human eye such as lacrimal secretion and blinking reflex, which leads to rapid drainage of the medication. Combination between the low pre-corneal contact time and corneal impermeability results in poor bioavailability (1-3\%) so, frequent dosing is usually needed ${ }^{3}$.

According to that, there is a need for an acceptable delivery system that increases the contact time of the drug with the eye surface and facilitates the transport of drug molecules into the eye tissue. In this role, a controlled or sustained delivery of ophthalmic medicine would be useful. variety of mixture drug delivery systems like liposomes, chemical compound micelles, nanocapsules, and NPs are described for improving ocular bioavailability ${ }^{4}$.

Nanoparticles (NPs) represent promising drug carriers for ophthalmic applications. After ideal binding to these particles, the drug absorption in the eye is enhanced significantly in comparison with that of eye drop solutions owing to the much slower ocular elimination

Received in 23/2/2020 \& Accepted in 10/5/2020 
rate of particles. Smaller particles are better tolerated by patients than larger particles, therefore NPs may represent very comfortable ophthalmic prolonged action delivery systems 5 . Nanoparticle-laden fluid, also known as Nanofluid, has served in a wide range of engineering applications, for example porous materials $^{6-8}$, fuel-cell industry ${ }^{9 \& 10}$, petroleum engineering $^{11 \& 12}$, and medical treatment ${ }^{13-15}$, etc. due to its significant increase in a number of properties of the fluid, such as permeability, heat-transfer rate, chemical stability, etc., compared to conventional engineered fluid ${ }^{16}$. Thus, nanofluid can be implemented for a more-stable, more-sustainable, and moreefficient KT delivery. The main disadvantage of NPs is the tendency to agglomerate during storage, especially in liquid formulations. This inconvenience is frequently overcome by freeze-drying ${ }^{17}$.

Eudragit $^{\circledR}$ RL 100 is used to develop controlled and sustained release formulations. It is a co-polymer of poly (ethyl acrylate, methyl-methacrylate, and chlorotrimethylammonioethyl methacrylate) with many quaternary ammonium groups, that give a surface positive charge. It is insoluble in the physiological $\mathrm{pH}$ and able to swell, making itself a suitable material for the drug dispersion. This feature may subsequently increase the drug-polymer complex's cellular uptake. Eudragit $^{\mathbb{B}^{(}}$RL 100, therefore, appears to be a promising polymer for controlled and prolonged localized delivery of a desired medicine to certain physiological fluids ${ }^{18}$. Previously, eudragit ${ }^{\circledR}$ RL 100 was used to deliver anti-inflammatory drugs ${ }^{19-22}$.

Gelatin is a non-toxic natural chemical compound that encompasses a distinctive chemical structure with an oversized variety of helpful amino acids and useful functional groups, it's a biocompatible and biodegradable chemical compound with no harmful byproducts. With chemical modification and crosslinking, it will produce new chances for safe drug delivery nanocarrier synthesis and resultant drug loading ${ }^{23}$. Moreover, collagen (the native macromolecule from that gelatin springs) is found within the eye specifically within the stroma and the center cell layer of the membrane and has been extensively used in ocular applications ${ }^{24-26}$.
In the current study, KT - NPs based on eudragit RL 100 and gelatin were developed and evaluated for their in-vitro and ex-vivo performance within the eye.

\section{MATERIALS AND METHODS}

\section{Materials}

Ketorolac tromethamine was kindly supplied by European Egyptian Pharmaceutical Industrial Company, Egypt. Gelatin (type A 25000 KDa), eudragit RL 100 (Evonik Industries AG, Germany). Glutaraldehyde was obtained from (Sandoz Ltd. Mumbai.India). Ethanol, methanol, acetone and Tween 80 were obtained from El-Nasr Pharm. Chem. Co, Cairo., Egypt).

\section{Methods}

Preparation of KT nanoparticles ${ }^{27}$

\section{a) Eudragit RL 100 nanoparticles}

Eudragit RL 100 NPs (Table 1) were prepared by nanoprecipitation technique. One of the requirements of this method is that, both polymer and drug have to be insoluble in aqueous phase. However, entrapment of hydrophilic drug substances is very difficult in this technique and several methods were reported to improve drug entrapment efficiency of the nanoprecipitaion method. These methods include changing the $\mathrm{pH}$ of the aqueous phase, replacing the salt form of the drug with the base form. In brief, accurately weighed quantity of eudragit RL 100 (50,100 or 200 $\mathrm{mg}$ ) and $\mathrm{KT}(50$ or $100 \mathrm{mg}$ ) were dissolved in 5 $\mathrm{ml}$ organic phase (ethanol or methanol). This organic phase was poured with constant speed $(0.5 \mathrm{ml} / \mathrm{min})$ into $20 \mathrm{ml}$ aqueous phase (distilled water or citrate buffer at $\mathrm{pH} 5$ or 3 ) containing $0.1 \% \mathrm{w} / \mathrm{v}$ Tween 80 as hydrophilic surfactant, under moderate magnetic stirring at $900 \mathrm{rpm}$ (Magnetic stirrer with hot plate, Sybron/Thermolyne Co., Dubuque lowa, USA). NPs formed and convert into opaque colloidal solution. The resulting dispersion was stirred at room temperature overnight with a magnetic stirrer to permit evaporation of organic phase (ethanol or methanol). The eudragit NPs were lyophilized to induce free-flowing powder ${ }^{27 \& 28}$.

\section{b) Gelatin nanoparticles}

Gelatin NPs (Table 2) were prepared by a two-step desolvation technique. At first, gelatin 
Table 1: Composition of eudragit RL 100 KT loaded NPs.

\begin{tabular}{||c|c|c|c|c||}
\hline $\begin{array}{c}\text { Formula Code } \\
\text { (eudragit RL } \\
\text { 100 NPs) }\end{array}$ & \multicolumn{2}{|c|}{$\begin{array}{c}\text { K T : Eudragit RL } \\
(1: 1 \text { or 2) }\end{array}$} & Organic phase & Aqueous phase \\
\hline E1 & $50 \mathrm{mg}$ & $50 \mathrm{mg}$ & ethanol & Dist. Water \\
\hline E2 & $50 \mathrm{mg}$ & $50 \mathrm{mg}$ & ethanol & Citrate buffer $\mathrm{pH} \mathrm{5}$ \\
\hline E3 & $50 \mathrm{mg}$ & $50 \mathrm{mg}$ & ethanol & Citrate buffer $\mathrm{pH} \mathrm{3}$ \\
\hline E4 & $50 \mathrm{mg}$ & $100 \mathrm{mg}$ & ethanol & Citrate buffer $\mathrm{pH} \mathrm{3}$ \\
\hline E5 & $100 \mathrm{mg}$ & $200 \mathrm{mg}$ & ethanol & Citrate buffer $\mathrm{pH} \mathrm{3}$ \\
\hline E6 & $50 \mathrm{mg}$ & $100 \mathrm{mg}$ & methanol & Citrate buffer pH 3 \\
\hline
\end{tabular}

Table 2: Composition of gelatin KT-loaded NPs.

\begin{tabular}{|c|c|c|c||}
\hline $\begin{array}{c}\text { Formula code } \\
\text { (gelatin NPs) }\end{array}$ & \multicolumn{2}{|c|}{ KT : Gelatin } & $\begin{array}{c}\text { Glutaraldehyde } \\
(1: 1,2 \text { or } 3)\end{array}$ \\
\hline G1 & $50 \mathrm{mg}$ & $50 \mathrm{mg}$ & - \\
\hline G2 & $50 \mathrm{mg}$ & $50 \mathrm{mg}$ & $0.2 \mathrm{ml}$ \\
\hline G3 & $50 \mathrm{mg}$ & $100 \mathrm{mg}$ & $0.2 \mathrm{ml}$ \\
\hline G4 & $50 \mathrm{mg}$ & $150 \mathrm{mg}$ & $0.2 \mathrm{ml}$ \\
\hline G5 & $100 \mathrm{mg}$ & $50 \mathrm{mg}$ & $0.2 \mathrm{ml}$ \\
\hline
\end{tabular}

(50, 100 or $150 \mathrm{mg}$ ) was dissolved in $10 \mathrm{ml}$ distilled water, under conditions of heating at $40 \pm 1{ }^{\circ} \mathrm{C}$ stirring until a clear solution was obtained. Then, $10 \mathrm{ml}$ acetone was added to the gelatin solution as a dissolving agent to precipitate the high molecular weight gelatin. Then discard the white supernatant. Redissolving the precipitated high molecules weight gelatin in $10 \mathrm{ml}$ in an aqueous solution of KT $\left(50\right.$ or $100 \mathrm{mg}$ ) at $40^{\circ} \mathrm{C}$ and the $\mathrm{pH}$ of the resultant solution was adjusted to 3.0 by adding conc $\mathrm{HCl}$ (Digital pH, Jenway Ltd., Felsted, Dunmow, Essex. M63LB, UK). 10 ml acetone was added drop wisely with constant stirring for $20 \mathrm{~min}$. Gelatin NPs were formed in situ after the addition of acetone. $0.2 \mathrm{ml}$ of glutaraldehyde ( $25 \%$ aqueous solution) was added after $10 \mathrm{~min}$ of addition of acetone, to crosslink NPs. By heating in a water bath at $50^{\circ} \mathrm{C}$, the acetone was removed. Nanoparticles were subjected to purification by centrifugation at $5000 \mathrm{rpm}$ for $20 \mathrm{~min}$, washed three times with distilled water. The purified residue was redispersed in an aqueous solution and lyophilized to get free-flowing powder ${ }^{29}$.

\section{Lyophilization of NPs}

Lyophilization technique involved stabilization stage $\left(+10^{\circ} \mathrm{C}\right.$ for $\left.1 \mathrm{hr}\right)$, freezing $\left(-55^{\circ} \mathrm{C}\right.$ for $\left.4 \mathrm{hrs}\right)$, primary drying $\mathrm{I}\left(-25^{\circ} \mathrm{C}\right.$ for $37 \mathrm{hrs})$, primary drying II $\left(+20^{\circ} \mathrm{C}\right.$ for $\left.5 \mathrm{hrs}\right)$ and secondary drying $\left(+20^{\circ} \mathrm{C}\right.$ for $\left.6 \mathrm{hrs}\right)$ using a Telstar LyoQuest freeze dryer ${ }^{30}$ (Martin Christ $\mathrm{GmbH}$, Osterode, Germany).

\section{Determination of entrapment efficiency (\%EE)}

The amount of drug trapped in the nanoparticles (NPs) was determined by calculating the difference between the total quantity of KT used in NPs preparing and the quantity of drugs still dissolved in the aqueous dispersion medium. Three milliliters of KTloaded nano dispersions were centrifuged at $14000 \mathrm{rpm}$ and $4^{\circ} \mathrm{C}$ for $60 \mathrm{~min}$ (Ultracentrifuge, Microlitre centrifuge, Micro200R, Germany). The supernatant was analyzed for the free drug spectrophotometerically at $\lambda_{\max } 322 \mathrm{~nm}$. The drug entrapment efficiency (\%EE) was calculated from the equation below

$$
\% \mathrm{EE}=(\mathrm{A}-\mathrm{B} / \mathrm{A}) \times 100^{5}
$$

Where $\mathrm{A}$ is the total amount of drug in the nano dispersion and $\mathrm{B}$ is the free amount of drug in the supernatant. 


\begin{abstract}
Particle size and Zeta potential measurement

Dynamic light scattering (DLS) was used to determine the particle size and polydispersity index (PDI) of the prepared NPs using Malvern Zeta sizer 3000 HSA (London, $\mathrm{UK})$ at $25^{\circ} \mathrm{C}$. Zeta potential was measured under the same conditions using Laser Doppler Electrophoresis (LDE). The mean hydrodynamic diameter (MHD) was reported as the size values. All measurements were carried out on at least three separate preparations $^{31}$.
\end{abstract}

\section{Morphological evaluation}

Scanning electron microscopy (SEM) examined the particle shape and surface morphology of nanoparticles. Lyophilized and completely moisture-free samples were collected using adhesive tapes on aluminum stubs and coated with gold using sputter coaters (JEOL auto fine coater, Japan) and observed for morphology at $20 \mathrm{kV}$ acceleration voltage $^{32}$.

\section{Differential scanning calorimetry (DSC)}

A Differential Scanning Calorimeter (DSC-60, Shimadzu, Japan) connected to a computerized thermal analyzer was used to obtain DSC thermograms of the KT, eudragit RL 100, gelatin, 1:1 physical mixtures and thermal behavior of the drug in nanoparticles. Analyzed the drug's endothermal transition using thermo gravimetry ${ }^{33}$.

\section{Fourier transforms infrared (FTIR) spectroscopy analysis}

Fourier transforms infrared (FTIR) analysis (Perkin Elmer, FT-IR Spectrometer, SPECTRUM RX I, USA) can determine the chemical integrity and possible chemical interaction between the drug and the polymer. Samples were mixed separately with potassium bromide (200-400 mg) and compressed by applying hydraulic press pressure of 200 $\mathrm{kg} / \mathrm{cm}^{2}$ to prepare the pellets for $2 \mathrm{~min}$. Samples (KT, eudragit RL 100, gelatin, 1:1 KT : eudragit RL 100 or gelatin physical mixtures and KT loaded NPs) were scanned with average resolution of 32 interferograms of 2 $\mathrm{cm}^{-1}$ in the $4000-400 \mathrm{~cm}^{-1}$ range ${ }^{18}$.

\section{Powder X-ray diffractometry}

Diffraction Powder X-ray diffraction patterns (XRD) were studied to check the physical state of pure KT in the nanoparticle. The comparative study was performed with KT, eudragit RL 100, gelatin, 1:1 physical mixtures and nanoparticles using an X-ray diffractometer (XRD, X'pert pro, PanAnalytical, Netherland). The equipment equipped with a graphite crystal monochromator $\left(\mathrm{CuK}_{1}\right)$ (a voltage of $35 \mathrm{KV}$ and a current of $20 \mathrm{~mA}$ ) radiations to examine the physical state of the KT in $\mathrm{NPs}^{34}$. The scanning rate was $10^{\circ} \mathrm{C} / \mathrm{min}$ over the range of $0-60^{\circ}$ at $25^{\circ} \mathrm{C}$ in the whole study.

\section{In-vitro release of KT from nanoparticles}

The in-vitro release was done using thermostatically controlled shaker (Gesellschaft labor technic M.B.H \& GFL, Germany). Samples of one ml of KT-loaded nanodispersion were placed in glass cylindrical tubes with one end tightly covered with a cellophane membrane soaked overnight in phosphate buffer solution (PBS) pH 7.4 and the other end is free. The glass tubes have been dipped into $100 \mathrm{ml} \mathrm{PBS} \mathrm{(pH} \mathrm{7.4).} \mathrm{The} \mathrm{release}$ study was carried out at $37 \pm 0.5^{\circ} \mathrm{C}$, and the stirring shafts rotated at a speed of $25 \mathrm{rpm}$. Aliquots of $5 \mathrm{ml}$ of the release medium were collected at predetermined time intervals $(0.25$, $0.5,1,1.5,2,3,4,6$ and $8 \mathrm{hrs}$ ) and replaced with equal volumes of PBS. The collected samples were analyzed for drug content spectrophotometrically (UV-Spectrophotometer, Shimadzu-50-02, Kyoto, Japan) at $\lambda_{\max }$ $322 \mathrm{~nm}$ against the samples withdrawn at a respective time intervals from plain nanocarrier dispersions treated by the same manner. The experiment was performed in triplicate, and the percentage of released KT was calculated ${ }^{35}$.

\section{Drug release kinetics}

To understand the kinetics and drug release mechanism from NPs. in-vitro drug release data from drug loaded eudragit RL 100 and gelatin NPs were fitted into four primarily applied mathematical models (mentioned below) to estimate KT release kinetics from prepared eudragit RL 100 and gelatin nan oparticles: 
Zero-order model

First-order model

$$
D_{t}=D_{0}+k_{0} t
$$$$
D_{t}=\operatorname{In} D_{0}+k_{1} t
$$

Higuchi square root model $D_{t}=D_{0}+k_{H} t^{1 / 2}$

Korsmeyer-Peppas model $D_{t} / D_{1}=D_{0}+k_{P} t^{n}$

where $\mathrm{D}_{t}$ is the amount of drug released at time $\mathrm{t}, \mathrm{D}_{0}$ is the initial amount of drug released, $D_{t} / D$ is fraction of drug released at time $\mathrm{t}, k_{0}$ is the zero-order release constant, $k_{1}$ is the firstorder release constant, $k_{H}$ is the Higuchi release constant, $\mathrm{K}_{\mathrm{p}}$ is the Peppas release constant, and $\mathrm{n}$ is the release exponent respectively ${ }^{36-38}$.

\section{Permeability study of KT through rabbit corneal membrane}

For measuring corneal permeability, glass diffusion cells were made from $50 \mathrm{ml}$ Erlenmeyer flasks (Franz Transdermal Diffusion Cell Drive Console, Perme Gear, Inc., Hellertown, PA, USA). The end of the side arm projection on each half-cell had a ground-glass ended with a circular opening in the middle. The cross-sectional surface area of this opening was $0.385 \mathrm{~cm}^{2}$. The study was performed in male albino rabbits. Rabbits eyes were examined for any visual defects. Rabbits were sacrificed, the whole eye enucleated and the corneas were removed, then gently, flushed with normal saline. The cornea was positioned on the donor half-cell such that the epithelial surface facing the donor solution. The receptor half-cell was positioned symmetrically opposite to the donor half-cell. The half cells were secured together with a clamp. This procedure prevents any leaks. After the cornea was secured mounted, $50 \mathrm{ml}$ phosphate buffer solution ( $\mathrm{pH}$ 7.4) was first added to the receptor cell, similarly, $20 \mathrm{ml}$ of NPs formulation (lyophilized powder dissolved in isotonic saline solution $0.9 \% \mathrm{NaCl}$ ) added to the donor cell. Both cells were capped with aluminum foil to avert evaporation. The entire apparatus was thermostated at $37^{\circ} \mathrm{C} \pm 0.5$. The donor and receptor solutions were stirred at $100 \mathrm{rpm}$ with magnetic stir bars. Samples (1 $\mathrm{ml}$ ) were withdrawn at different time intervals from the receptor compartment and replaced with fresh PBS for analysis of the drug penetrated. The amount of permeated KT across the cornea was quantified spectrophotometrically at $\lambda_{\max } 322 \mathrm{~nm}^{39}$.

Permeation parameters such as the cumulative amount of drug permeated (Qt), flux (Js, g/ $\mathrm{cm}^{2} / \mathrm{h}$, permeability coefficient $(\mathrm{Kp}$, $\mathrm{cm} / \mathrm{h}$ ), partition and diffusion parameters ( $\mathrm{P}$ and D) were also calculated ${ }^{29 \& 40 .}$ The mean cumulative amount of drug permeated per unit surface area of the cornea was plotted versus time. The slope of the linear portion of the plot was calculated. The rate of permeation (slope of the linear portion of the plot) divided by the area available for diffusion ${ }^{30}$.

$$
\mathrm{J}(\mathrm{flux})=(\mathrm{dM} / \mathrm{dt}) / \mathrm{A} \text { where }{ }^{36}
$$

$\mathrm{dM} / \mathrm{dt}$ is the rate of permeation (slope of linear portion of plot)

$\mathrm{A}$ is the area available for permeation $(0.385$ $\mathrm{cm}^{2}$ ).

Corneal permeability was calculated by dividing the steady state flux by the donor conc $\left(\mathrm{C}_{\mathrm{d}}\right)$ of $\mathrm{KT}$ according to the following equation

Apparent permeability coefficient $(\mathrm{P})=$ Flux / $\mathrm{C}_{\mathrm{d}}{ }^{41}$

\section{Histological analysis}

Without damaging it, the cornea was carefully separated from the eye and rinsed with phosphate buffer solution (PBS). Tissues were fixed overnight at 4 Co using $4 \%$ paraformaldehyde (PF) and washed in PBS. The tissue segments were dehydrated using graded ethanol, embedded in paraffin and cut sections with a microtome of 5-7 $\mathrm{mm}$ thick. Sections were collected using the Leica cryostat on polylysine-coated slides and instantly fixed in ice-cold acetone All the sections were stained with hematoxylin-eosin (H\&E) for analysis ${ }^{42}$.

\section{Stability of the prepared NPs}

KT loaded NP samples (E4 and G 3) were stored in clean, $20 \mathrm{~mL}$ glass vials were capped for 3 months at two different temperatures (4 and $25^{\circ} \mathrm{C}$ ). The stored samples were visually inspected for appearance, color change and evaluated for particle size and entrapment efficiency (\%EE) at specified time intervals 0 , 1, 2 and 3 months).

\section{Statistical analysis}

A one-way variance analysis (ANOVA) by GraphPad Software Version 3.05, San Diego, CA was used to perform statistical analysis. The p-value of 0.05 was considered statistically significant. 


\section{RESULTS AND DISCUSSION}

\section{Evaluation of KT-loaded nanoparticles \\ Drug entrapment efficiency (\%EE)}

Generally, the entrapment efficiency (\%EE) of nanoparticles is influenced by the characteristics of the polymer: drug ratio, type of organic phase, $\mathrm{pH}$ of aqueous phase etc (Table 3). It has been shown that, an increase in polymer concentration in the organic phase enhances drug entrapping $(p<0.05)$ due to an increase in organic phase viscosity, which increases diffusional resistance to drug molecules from organic phase to aqueous phase, resulting in more drugs being entrapped in NPs ${ }^{29}$. Additional increasing in the polymer ratio showed a decreased or insignificant change $(p<0.05)$ in the efficiency of drug entrapping. The increasing in polymer concentration is believed to have resulted in the formation of more compact polymer coat, which has prevented proper drug entrapping ${ }^{43}$.

The type of organic phase also affected on the entrapment efficiency of the drug. E4 showed higher \%EE than E6, which may be attributed to that ethanol (B.P of $78^{\circ} \mathrm{C}$ ) tends to evaporate slower than methanol (B.P of $64^{\circ} \mathrm{C}$ ). Based on the belief that, the drug loss to the aqueous phase is slow as long as the organic solvent is present as droplets and increases once the solvent is removed, the drug loss to the aqueous phase decreased on using ethanol as organic phase resulting in higher entrapment efficiency ${ }^{44}$.

The solubility of the drug in the aqueous phase is considered one of the main factors that could affect the drug entrapment in NPs. KT has a good solubility in water, thus, when the organic phase was added dropwise into the aqueous surfactant solution, part of the drug was ionized and escaped from the nanoparticles during diffusion of the ethanol into the aqueous phase. The aim of using citrate buffer ( $\mathrm{pH} 3)$ was to make an insoluble medium for KT. KT having $\mathrm{pKa}$ of 3.5 is practically insoluble in acidic $\mathrm{pH}$ of 3 . So, the drug loss is limited to the aqueous phase, thus increasing the entrapment efficiency ${ }^{45 \& 46}(p<0.05)$.

For gelatin NPs (Table 3), G1 displayed highest entrapment efficiency $(p<0.05)$ in comparison to other NPs. G1 showed $58.4 \pm 2.1 \%$ drug entrapment while $\mathrm{G} 2$ showed $44.3 \pm 3.4 \%$. This reduction in the entrapping can be attributed due to using glutaraldehyde as crosslinker, the successful crosslinking of nanoparticles, particles become dense as glutaraldehyde forms numerous hydrogen bonds with single nanoparticles, leaving less compartment for drug entrapping ${ }^{19}$.

\section{Particle size, Zeta potential and size distribution}

For ocular administration, the prepared NPs were intended. Consequently, particle size and particle size distribution are essential parameters for the safe administration of such a formulation. Particle size should not exceed 10 $\mu \mathrm{m}$ for ophthalmic application ${ }^{47}$. Particle size is an important parameter because it has direct relevance to formulation stability, even larger particles tend to aggregate more than smaller particles, resulting in sedimentation. It was revealed that as drug: polymer ratio increased from $1: 1$ to $1: 2,1: 3$ particle size (Table 3 ) increased significantly $(p<0.05)$ from $178 \pm 8$ $\mathrm{nm}$ to $290 \pm 21 \mathrm{~nm}$ in case of eudragit RL 100 NPs and from $360 \pm 12 \mathrm{~nm}$ to $430 \pm 21 \mathrm{~nm}$ for gelatin NPs. The smaller particle size at low polymer content (E3 \& G2) might be because of the high efficiency of the organic polymersolvent phase in the aqueous phase. Increased organic phase viscosity with increasing polymer content also gives resistance to mass transfer in turn diffusion of the polymersolvent phase into the aqueous phase leading to particle enlargement (E4 \& G4) ${ }^{48}$.

All the formulations exhibited positive zeta potential values (Table 3 ), such a positive charge is supposed to be important, since it can facilitate an effective adhesion to the cornea surface. The increasing in eudragit mass ratio resulted in enhancing zeta potential from $21.4 \pm 0.8 \mathrm{mV}$ (E3) to $26.5 \pm 1.1 \mathrm{mV}$ (E4) ( $p<$ $0.05)$, this was presumed to be due to the availability of unbound amino groups which contributed to accelerate positive charge ${ }^{49}$. Gelatin is a polyelectrolyte that contains anionic as well as cationic groups. The net charge is dependent on the $\mathrm{pH}$ solution. Gelatin chains are linked to form stable nanoparticles during the formation of nanoparticles. Accordingly, the zeta potential profile of gelatin nanoparticles at different $\mathrm{pH}$ values shows that ionized cationic groups predominate at lower $\mathrm{pH}$, making the overall surface positively charged, $12.4 \pm 2.1 \mathrm{mV}$ (G5) to $22.4 \pm 0.8 \mathrm{mV}$ (G4). 
Table 3: Particle Size (P.Z), Zeta Potential (Z.P), polydispersibity Index (PDI) and Entrapment Efficiency $(\%)$ of KT loaded nanoparticles.

\begin{tabular}{|c|c|c|c|c|}
\hline $\begin{array}{c}\text { Formula } \\
\text { No. }\end{array}$ & $\begin{array}{c}\text { Particle size } \\
(\mathrm{nm})\end{array}$ & $\begin{array}{c}\text { Zeta potential } \\
(\mathrm{mV})\end{array}$ & PDI & $\begin{array}{c}\text { Entrapment } \\
\text { efficiency }(\%)\end{array}$ \\
\hline E1 & - & - & - & $18.4 \pm 1.4$ \\
\hline E2 & - & - & - & $26.8 \pm 2.1$ \\
\hline E3 & $178 \pm 18$ & $+21.4 \pm 0.8$ & $0.31 \pm 0.02$ & $61.7 \pm 2.5$ \\
\hline E4 & $290 \pm 21$ & $+26.5 \pm 1.1$ & $0.21 \pm 0.01$ & $71.3 \pm 3.2$ \\
\hline E5 & $260 \pm 19$ & $+24.7 \pm 1.2$ & $0.23 \pm 0.02$ & $64.4 \pm 3.7$ \\
\hline E6 & - & - & - & $50.4 \pm 2.1$ \\
\hline G1 & $530 \pm 13$ & $+18.5 \pm 0.4$ & $0.32 \pm 0.06$ & $58.4 \pm 2.1$ \\
\hline G2 & $360 \pm 12$ & $+16.7 \pm 0.6$ & $0.24 \pm 0.04$ & $44.3 \pm 3.4$ \\
\hline G3 & $380 \pm 15$ & $+22.4 \pm 0.8$ & $0.22 \pm 0.03$ & $53.5 \pm 5.1$ \\
\hline G4 & $430 \pm 21$ & $+24.2 \pm 1.2$ & $0.21 \pm 0.04$ & $47.5 \pm 3.5$ \\
\hline G5 & $395 \pm 14$ & $+12.4 \pm 2.1$ & $0.21 \pm 0.03$ & $48.2 \pm 2.4$ \\
\hline \hline
\end{tabular}

Colloidal dispersions are subject to several kinds of instability. The particles can stick to each other (aggregation, coagulation, flocculation), they can stick to surrounding surfaces (deposition) and they can separate under gravity (sedimentation or creaming). These mechanisms all can be counteracted by strong electrostatic repulsion, and the strength of that repulsion can be parameterized by the zeta potential. Strong electrostatic repulsion can prevent aggregation by keeping colloidal particles well separated from each other and from surfaces. It is a general rule of thumb that an absolute value of zeta potential above 60 $\mathrm{mV}$ yields excellent stability, while 30, 20 and less than $5 \mathrm{mV}$ generally results in good stability, acceptable short term stability and fast particle aggregation, respectively ${ }^{50}$.

\section{Surface morphology}

For determination of the accurate diameter of NPs, SEM method was used,this technique gives information regarding surface morphology of the $\mathrm{NPs}^{51-54}$, SEM images for eudragit RL 100 NPs and gelatin NPs are shown in figures $1 \& 2$. The prepared nanoparticles were nearly spherical in shape with a smooth surface. These particles are not expected to cause any irritation to ocular surface, as it is known that isometric particles with obtuse angles and edges cause less irritation than particles with sharp angles and edges $^{43}$, NPs separated from each other, suggesting possible stabilization of the NPs due to positive surface charges. It also confirmed the particle size range, which was obtained by Zeta sizer.

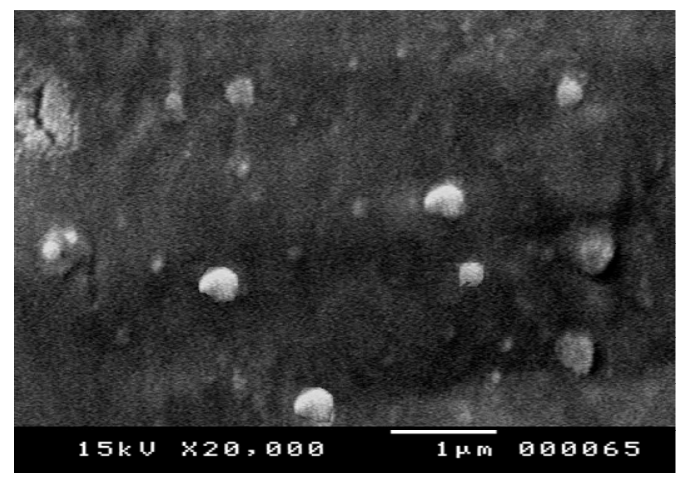

Fig. 1: Scanning electron photomicrograph of eudragit RL 100 NPs.

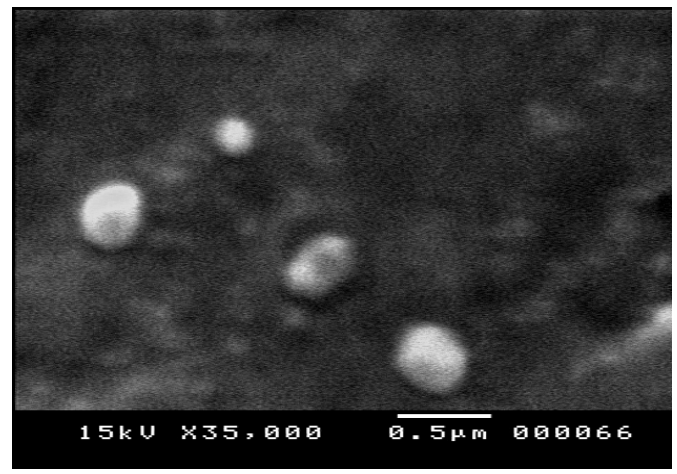

Fig. 2: Scanning electron photomicrograph of gelatin NPs.

\section{Physicochemical characterizations}

Differential scanning calorimetry (DSC), Fourier transforms infrared (FTIR) 
spectroscopy and Powder X-ray diffractometry (XRPD) experiments were aimed at inspecting crystallinity properties as well as examining possible drug-polymer interactions in the prepared NPs. Figure 3 demonstrates DSC thermograms of KT, eudragit RL 100, gelatin, their PM, and drug loaded NP formulations. KT shows an endothermic peak at $168.9 \mathrm{C}$, peak associated with KT's melting point. The KT physical mixture with eudragit RL 100 or gelatin, showed the same melting behavior $\left(168.2^{\circ} \mathrm{C}\right)$ showing no chemical interaction between drug and polymer. Nonetheless, in the thermogram obtained with the KT-loaded NPs, the endothermic peak characteristic of KT was not identified which indicates that KT was presumably trapped in the amorphous form within the NPs ${ }^{55}$.

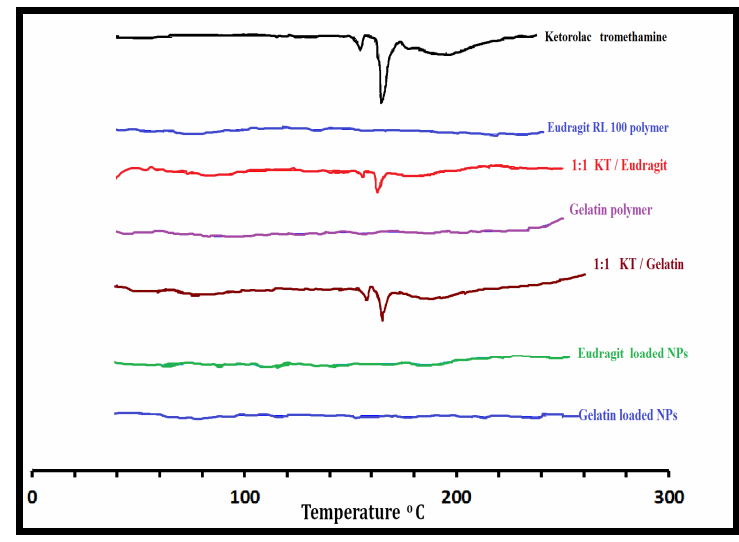

Fig. 3: DSC thermograms for KT, eudragit RL 100, gelatin, physical mixtures, eudragit RL 100 NPs and gelatin loaded-NPs.

Fourier transforms infrared analysis characterizes materials and is especially useful recognizing inorganic mixtures and can provide molecular and structural information about organic and inorganic materials ${ }^{56}$, FTIR spectra (Fig. 4) was obtained over a range of 4000-500 $\mathrm{cm}^{-1}$ for KT, eudragit RL 100, gelatin, physical mixtures and drug-loaded NP formulations. Figure 4 demonstrates significant peaks (3341 $\mathrm{cm}^{-1}$; NH stretch, $1145 \mathrm{~cm}^{-1}$; C-O stretch (diarylketone) and $1611 \mathrm{~cm}^{-1}$ within the $\mathrm{KT}$ spectrum, most likely due to aromatic $\mathrm{C}-\mathrm{C}$ stretching). KT loaded NPs mainly showed eudragit RL 100 and gelatin absorption peaks with few KT covering peaks, indicated that, the drug entrapped within NPs.

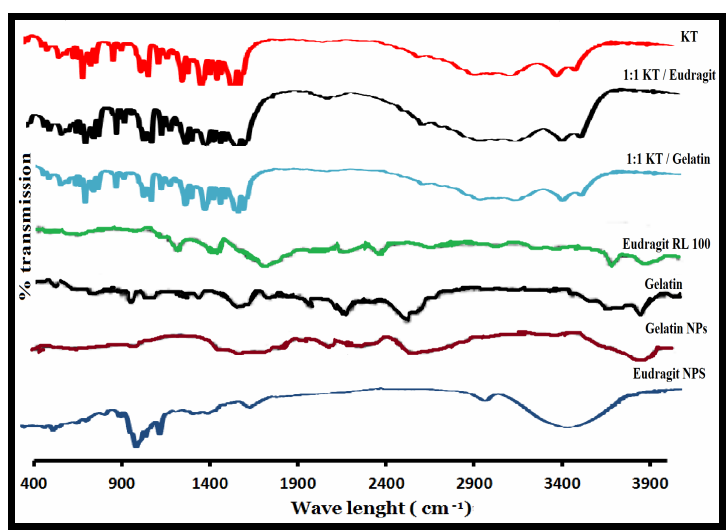

Fig. 4: FTIR spectra of KT, eudragit ${ }^{\circledR}$ RL 100, gelatin, physical mixtures, eudragit RL 100 NPs and gelatin NPs.

X-ray diffraction is frequently used to analyze the crystallinity of the sample ${ }^{56}$. As indicated by X-ray examinations (Fig. 5), the intact ketorolac showed distinct peaks at theta $9,12,12.4,18,20,23,23,28$ and 36 respectively, although there was no clear peak for amorphous polymer in X-ray diffractograms. The physical mixtures' X-ray spectra revealed that the intensities of typical peaks for intact drugs were diminished by increasing the eudragit and gelatin weight proportion due to the dilution. The nanoparticles prepared with eudragit or gelatin were characterized by the absence (or weakness) of distinct diffraction KT peaks, which meant an amorphous drug state or entrapped drug. X-ray results demonstrated consistency with DSC analysis findings. Specifically, the DSC and PXRD studies verified a diminish in in nanoparticles' drug crystallinity.

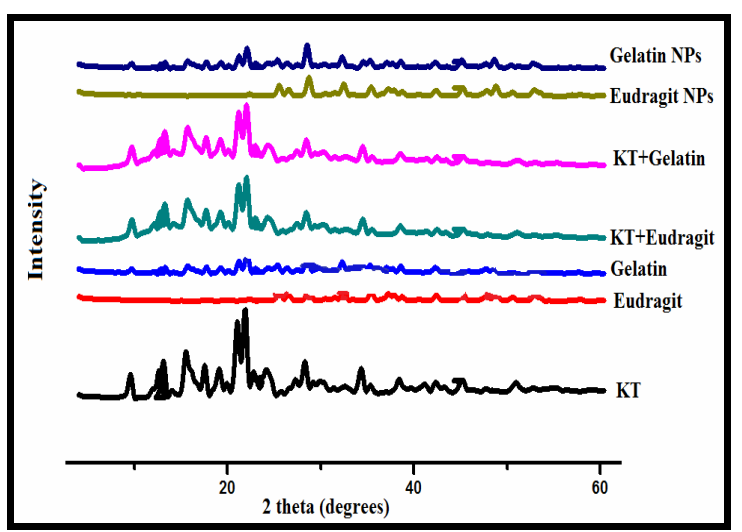

Fig. 5: XRPD spectrums of KT, eudragit RL 100, gelatin, physical mixtures, eudragit RL 100 NPs and gelatin NPs. 


\section{In-vitro release of KT from NPs}

In-vitro drug release profiles of KT from eudragit RL 100 NPs (E3, E4, and E5) and from gelatin NPs (G2, G3 and G5) that had smaller particle size and higher \%EE contrasted with release of KT from the commercial eye solution $\left(\right.$ Acular $^{\circledR}$ ) are graphically illustrated in figure 6. A rapid release of KT was observed from Acular ${ }^{\circledR}$ eye drops, where about $100 \%$ of KT was released after $3 \mathrm{hrs}$. This was expected in the knowledge that Acular $^{\circledR}$ is an isotonic aqueous KT solution. On the other hand, all eudragit NPs (E3, E4 and E5) and gelatin NPs (G2, G3 and G5) showed a prolonged release $(p<0.05) ; 62$, 55 and $52 \%$ of drug was released from eudragit NPs and 36, 42 and 38\% from gelatin NPs respectively within $8 \mathrm{hrs}$. This result suggests that the drug is strongly entrapped in eudragit RL 100 and gelatin NPs, demonstrating that a compact wall of the polymer is formed around the drug ${ }^{57}$. As the drug : polymer ratio is changed from $1: 1$ to $1: 2$ (i.e. as the concentration of polymer increases) the drug release was substantially sustained $(p<0.05)$; These results might be due to the increase in the polymer concentration resulted in an increase in the polymer thickness of the nanoparticles leading to an increase in the pathway length through the polymer membrane for the drug to reach to the surface of the nanoparticles ${ }^{28}$.

Eudragit RL 100 NPs showed significantly higher release $(p<0.05)$ than gelatin NPs, as eudragit RL 100 NPs have smaller particle size than gelatin NPs which give more surface area for release and long pathway length in case of gelatin NPs $^{28 \& 45}$.

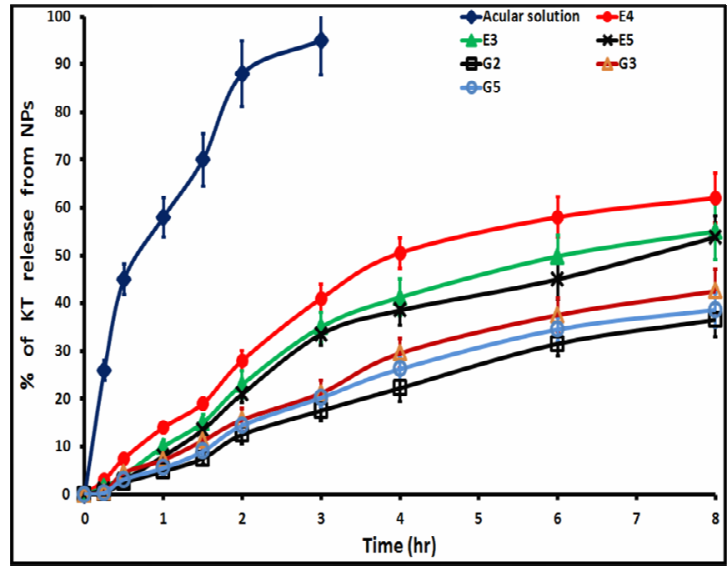

Fig. 6: The in-vitro drug release from KT loaded NPs in phosphate buffer $\mathrm{pH} 7.4$ (mean \pm S.D.; $n=3$ ) of formulations eudragit RL 100 NPs (E3, E4, and E5), gelatin NPs (G2, G3, G5) and acular ${ }^{\circledR}$ solution.

The release data were fitted into various kinetic models like zero-order, first-order, Higuchi and Korsmeyer-Peppas equations in order to determine the release mechanism and regression coefficients $(\mathrm{R})$. The release of KT from eudragit RL 100 and gelatin NPs fitted best to Higuchi-square-root release kinetics, which can be confirmed by comparing the values for the regression coefficient (Table 4). The estimation of ' $n$ ' $(0.45<n<0.82)$, the diffusion exponent of Korsmeyer-Peppas equation indicated that the release of KT from NPs is anomalous, i.e. contributed by mix of disintegration and dissemination.

Table 4: Model fitting for the release profile of KT from eudragit and gelatin NPs.

\begin{tabular}{|c|c|c|c|c|c|}
\hline \multirow{2}{*}{$\begin{array}{c}\text { Formulation } \\
\text { code }\end{array}$} & $\begin{array}{c}\text { Zero } \\
\text { order }\end{array}$ & $\begin{array}{c}\text { First } \\
\text { order }\end{array}$ & $\begin{array}{c}\text { Higuchi } \\
\text { matrix }\end{array}$ & $\begin{array}{c}\text { Korsmeyer } \\
\text {-Peppas }\end{array}$ & \multirow{2}{*}{ Best fit model } \\
\cline { 2 - 5 } & $\mathrm{R}^{2}$ & $\mathrm{R}^{2}$ & $\mathrm{R}^{2}$ & $\mathrm{R}^{2}$ & \\
\hline E3 & 0.943 & 0.982 & 0.990 & 0.980 & Higuchi \\
\hline E4 & 0.944 & 0.984 & 0.997 & 0.970 & Higuchi \\
\hline E5 & 0.947 & 0.981 & 0.987 & 0.975 & Higuchi \\
\hline G2 & 0.945 & 0.986 & 0.993 & 0.976 & Higuchi \\
\hline G3 & 0.948 & 0.985 & 0.992 & 0.984 & Higuchi \\
\hline G5 & 0.953 & 0.987 & 0.991 & 0.972 & Higuchi \\
\hline
\end{tabular}




\section{Ex-vivo permeation studies}

The ex-vivo transcorneal permeation was carried out (Fig. 7 and Table 5), which indicated the improved permeation profile of the optimized formulation as compared with the Acular ${ }^{\circledR}$ solution. It may be attributed to the higher retention of NPs in the corneal surface due to their nano-dimensions ${ }^{58}$. Additionally smaller size offers several benefits like improved solubility, higher surface area, dissolution rate, corneal penetration, and bioadhesion of the nanomaterial $^{59}$. Particle size smaller than $10 \mu \mathrm{m}$ lowered eye irritation profile, tearing, and drainage of the administered drug as compared to larger particle with improved therapeutic profile in the treatment of the disease ${ }^{60}$. Permeability is a function of the flux and concentration of the drug in the donor recipient of the diffusion cell. In this part of the study, drug concentration is constant; thus, the difference is a consequence of flux. The flux $\mathrm{J}$ is actually proportional to the gradient of thermodynamic activity. This activity changes according to different formulations ${ }^{61}$.

Nanoparticles (E4 \& G3) showed the highest KT flux $70.1 \pm 5.7 \mu \mathrm{g} . \mathrm{cm}^{-2} \cdot \mathrm{h}^{-1}$ and $53.2 \pm 3.4 \mu \mathrm{g} . \mathrm{cm}^{-2} \mathrm{~h}^{-1}$ respectively, in spite of they exhibited the lowest $\mathrm{K} \quad 1.70 \pm 0.05$ and $1.84 \pm 0.05$ respectively and the increased permeation rate was a result of higher diffusion (D) $1.24 \pm 0.07 \mathrm{~cm}^{2} \cdot \mathrm{h}^{-1}$ and $0.75 \pm 0.02 \mathrm{~cm}^{2} \mathrm{~h}^{-1}$ respectively (Table 5). The diffusion coefficient D reflects the facility with which molecules move through the cornea and it is a function of the molecular structure of the diffusant. So it was concluded that the diffusion of KT through the cornea is the rate limiting step in permeation of KT. These results are in great concurrence with Gadad et al. ${ }^{62}$.

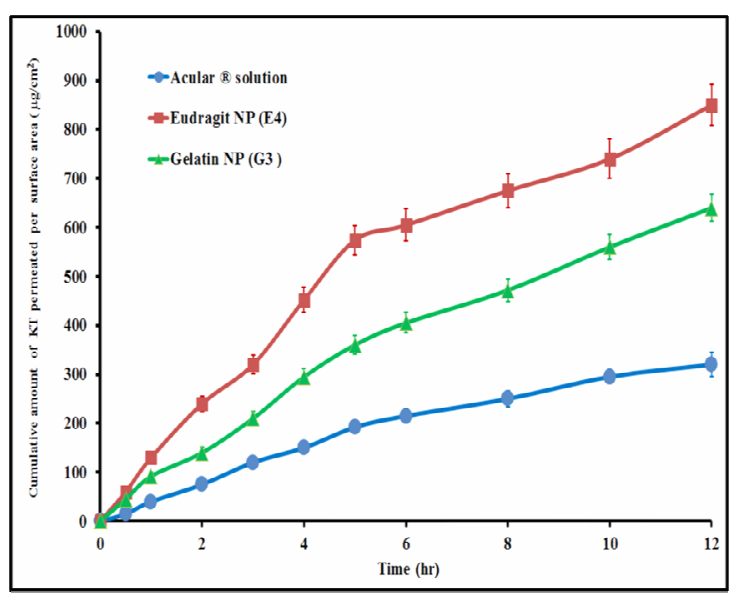

Fig. 7: Amount of KT permeated per surface area through rabbit cornea vs time.

\section{Histological analysis}

Microscopic histopathological analysis was used to evaluate cell structure and tissue integrity to detect irritation (Fig. 8); there were no differences in the appearance of the different tissues in the cornea being treated, some loose corneal stromal cells. These results indicate good biocompatibility of NPs with the eyes.

Table 5: Permeation parameters \pm SD of KT loaded NPs through rabbit corneal membrane.

\begin{tabular}{|c|c|c|c|c||}
\hline $\begin{array}{c}\text { Formulation } \\
\text { code }\end{array}$ & $\begin{array}{c}\text { Flux }(\mathrm{J}) \\
\left(\mu \mathrm{g} / \mathrm{cm}^{2} . \mathrm{h}\right) \times 10\end{array}$ & $\begin{array}{c}\text { Permeability } \\
\text { coefficient }(\mathrm{P}) \\
(\mathrm{cm} / \mathrm{h})\end{array}$ & $\begin{array}{c}\text { Diffusion } \\
\text { coefficient } \\
(\mathrm{D})\left(\mathrm{cm}^{2} / \mathrm{h}\right)\end{array}$ & $\begin{array}{c}\text { Partition } \\
\text { coefficient } \\
(\mathrm{K})\end{array}$ \\
\hline $\begin{array}{c}\text { Acular } \\
\text { solution }\end{array}$ & $2.76 \pm 0.11$ & $5.52 \pm 0.18$ & $0.42 \pm 0.02$ & $1.98 \pm 0.07$ \\
\hline $\mathrm{E} 4$ & $7.1 \pm 0.57$ & $14.2 \pm 1.43$ & $1.24 \pm 0.07$ & $1.70 \pm 0.05$ \\
\hline $\mathrm{G} 3$ & $5.32 \pm 0.34$ & $10.64 \pm 0.73$ & $0.75 \pm 0.02$ & $1.84 \pm 0.05$ \\
\hline
\end{tabular}


Table 6: Particle size and Entrapment efficiency (\%) of Eudragit RL 100 and gelatin nanoparticles within storage for 3 months at different conditions.

\begin{tabular}{|c|c|c|c|c|c|c|c|c|}
\hline \multirow{2}{*}{ Formula } & \multirow{2}{*}{ Parameter } & \multirow{2}{*}{$\begin{array}{c}\text { O month } \\
\text { (Fresh NPs) } \\
\end{array}$} & \multicolumn{2}{|c|}{1 month } & \multicolumn{2}{|c|}{2 months } & \multicolumn{2}{|c|}{3 months } \\
\hline & & & $4^{\circ} \mathrm{C}$ & $25^{\circ} \mathrm{C}$ & $4^{\circ} \mathrm{C}$ & $25^{\circ} \mathrm{C}$ & $4^{\circ} \mathrm{C}$ & $25^{\circ} \mathrm{C}$ \\
\hline \multirow[b]{2}{*}{ E4 } & $\begin{array}{l}\text { Particle size } \\
\quad \pm(\mathrm{SD})\end{array}$ & $290.0 \pm(21)$ & $303 \pm(20)$ & $300 \pm(24)$ & $307 \pm(18)$ & $310 \pm(19)$ & $310 \pm(17)$ & $315 \pm(18)$ \\
\hline & $\begin{array}{c}\% \mathrm{EE} \\
\pm(\mathrm{SD}) \\
\end{array}$ & $71.3 \pm(3.2)$ & $68.3 \pm(3.6)$ & $67.5 \pm(3.1)$ & $66.5 \pm(4.5)$ & $65.5 \pm(4.8)$ & $65 \pm(4.2)$ & $63.5 \pm(4.2)$ \\
\hline \multirow[b]{2}{*}{ G3 } & $\begin{array}{l}\text { Particle size } \\
\quad \pm(\mathrm{SD})\end{array}$ & $380 \pm(15)$ & $390 \pm(17)$ & $395 \pm(14)$ & $395 \pm(15)$ & $405 \pm(13)$ & $402 \pm(13)$ & $410 \pm(12)$ \\
\hline & $\begin{array}{l}\% \mathrm{EE} \\
\pm(\mathrm{SD})\end{array}$ & $53.5 \pm(5.1)$ & $52.8 \pm(4.2)$ & $52.4 \pm(4.6)$ & $52.5 \pm(4.8)$ & $51.8 \pm(3.7)$ & $52.1 \pm(5.2)$ & $51.4 \pm(4.1)$ \\
\hline
\end{tabular}

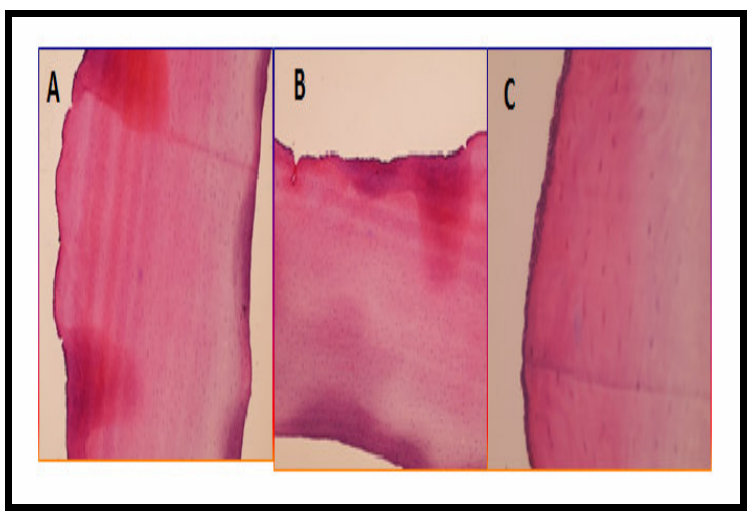

Fig. 8: Histopathology microscopy of the cornea treatment with different formulations, $\operatorname{Acular}^{\circledR}$ (A), Eudragit NPs (B) and Gelatin NPs $(C)$.

\section{Stability study}

The nanosuspensions produced sediment after storage, which was easy to redisperse through simple hand agitation. No changes were observed in the visible properties. There was an insignificant $(p<0.05)$ increase in particle size (Fig. 9A and Table 6) after 3 months of storage, possibly due to the aggregation of particles, and an insignificant $(p<0.05)$ reduction in the efficiency of particle entrapping (Fig. 9B and Table 6). It can be concluded from the above result that these NPs demonstrated good storage stability under different conditions. After long-term storage (3 months), they can be expected to be steady, safe and effective.

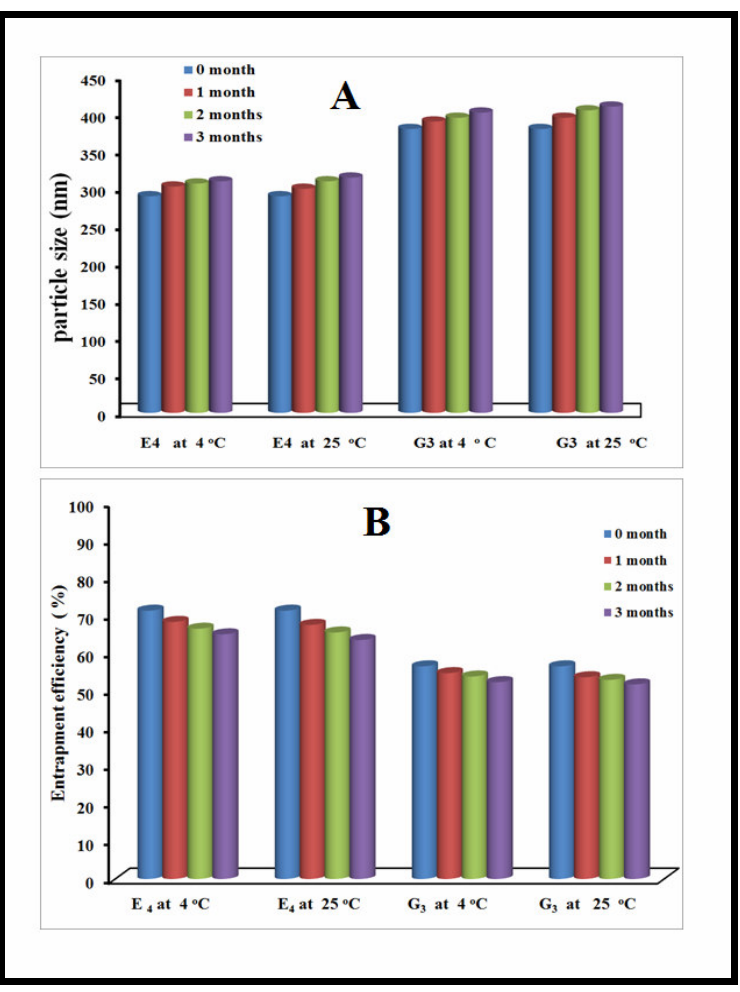

Fig. 9: Stability of KT nanoparticles during different conditions through 3 months, particle size (A) and entrapment efficiency (B). 


\section{Conclusion}

Ketorolac tromethamine based eudragit RL 100 and gelatin nanoparticles were formulated using two different methods. The optimized parameters have also been determined and were suitable for possible ocular application. Drug : polymer ratio was found to have an influence on particle size and entrapment efficiency. Particle size of NPs and PDI ranged from $187 \mathrm{~nm}$ to $530 \mathrm{~nm}$ and $0.2 \pm 0.01$ to $0.32 \pm 0.06$ respectively. The highest drug entrapment efficiency $(71.3 \pm 3.2 \%)$ was obtained in formulation E4, while formulation G3, prepared using KT : gelatin ratio of $1: 2$ at $\mathrm{pH} 3$ showed an entrapment efficiency of $53.5 \pm 5.1 \%$. In-vitro drug release in phosphate buffer solution at $\mathrm{pH}$ 7.4 showed sustained drug release over a period of $8 \mathrm{hrs}$ compared to $3 \mathrm{hrs}$ for acular ${ }^{\circledR}$ solution. Permeation data indicated that, KT permeation was significantly $(p<0.05)$ higher from E4 and G3 compared to Acular ${ }^{\circledR}$ solution with good ocular biocompatibility. After longterm storage (3 months), NPs can be expected to be steady, safe and effective. Overall; these results showed that, KT loaded NPs could be effective in sustaining drug release for a prolonged period of time and might be promising for improving the ocular bioavailability of KT.

\section{REFERENCES}

1- T. P. O'Brien, "Emerging guidelines for use of NSAID therapy to optimize cataract surgery patient care", Current Medical Research and Opinion, 21 (7), 113-1137 (2005).

2- X. Li, L. Du, X. Chen, P. Ge, Y. Wang, Y. Fu, H. Sun, Q. Jiang and Y. Jin, "Nasal delivery of analgesic ketorolac tromethamine thermo- and ion-sensitive in situ hydrogels", Int. J. Pharm., 489, 252260 (2015).

3- V. R. Sinha, R. V. Kumar and G. Singh, "Ketorolac tromethamine formulations: An overview", Expert Opin. Drug Deliv., 6, 961-975 (2009).

4- D. Achouri, A. Alhanout, P. Piccerelle and V. Andrieu, "Recent advances in ocular drug delivery", Drug Dev. Ind. Pharm., 39, 1599-1617 (2013).
5- S. Das, P. K. Suresh and R. Desmukh, "Design of Eudragit RL 100 nanoparticles by nanoprecipitation method for ocular drug delivery", Nanomedicine: Nanotechnology, Biology and Medicine, 6 (2), 318-323 (2010).

6- B. Xiao, W. Wang, X. Zhang, G. Long, J. Fan, H. Chen and L. Deng, "A novel fractal solution for permeability and Kozeny-Carman constant of fibrous porous media made up of solid particles and porous fibers", Powder Technology, 349, 92-98 (2019).

7- B. Xiao, X. Zhang, G. Jiang, G. Long, W. Wang, Y. Zhang and G. Liu, "KozenyCarman constant for gas flow through fibrous porous media by fractal-monte Carlo simulations", Fractals, 27 (4), 1-9 (2019).

8- M. Liang, C. Fu, B. Xiao, L. Luo and Z. Wang, "A fractal study for the effective electrolyte diffusion through charged porous media", International Journal of Heat and Mass Transfer, 137, 365-371 (2019).

9- M. Liang, Y. Liu, B. Xiao, S. Yang, Z. Wang and H. Han, "An analytical model for the transverse Permeability of gas diffusion layer with electrical double layer effects in proton exchange membrane fuel cells", International Journal of Hydrogen Energy, 43 (37), 17880-17888 (2018).

10- B. Xiao, W. Wang, X. Zhang, G. Long, H. Chen, H. Cai, L. Deng and Lin, "A Novel fractal model for relative permeability of gas diffusion layer in proton exchange membrane fuel cell with capillary pressure effect", Fractals, 27 (2), 1950012 (2019).

11- G. Long and G. Xu, "The effects of perforation erosion on practical Hydraulicfracturing applications", Society of Petroleum Engineers (SPE) Journal, 22 (2) 645-659 (2017).

12- G. Long, S. Liu, G. Xu, S. W. Wong, H. Chen and B. Xiao, "A Perforation-erosion model for hydraulic-fracturing applications", SPE Production and Operation, 33 (4), 770-783 (2018).

13- D. Su, R. Ma and L. Zhu, "Numerical study of nanofluid infusion in deformable tissues for hyperthermia cancer treatments", International Federation for 
Medical and Biological Engineering, 49, 1233-1240 (2011).

14- S. Soleymani, and R. Jalal, "ZnO nanofluids for the improved cytotoxicity and cellular uptake of doxorubicin", Nanomed. J., 5 (1), 27-35 (2018).

15- S. Kattupalli, "Nano Fluids: An innovative approach and potential applications", Journal de Afrikana, 4 (3), 454-472 (2017).

16- S. U. S. Choi and J. A. Eastman, "Enhancing thermal conductivity of fluids with nanoparticles", ASME, 66, 99-105 (1995).

17- M. Sameti, G. Bohr, M. N. Ravi Kumar, C. Kneuer, U. Bakowsky, M. Nacken, H. Schmidt and C. M. Lehr, "Stabilisation by freeze-drying of cationically modified silica nanoparticles for gene delivery", International Journal of Pharmaceutics, 266, 51-60 (2003).

18- U. Jana, A. K. Mohanty, P. K. Manna and G. P. Mohanta, "Preparation and characterization of nebivolol nanoparticles using Eudragit ${ }^{\circledR}$ RS100", Colloids and Surfaces B: Biointerfaces, 113, 269-275 (2014).

19- M. Ahuja, A. S. Dhake, S. K. Sharma and D. K. Majumdar, "Diclofenac-loaded eudragit S100 nanosuspension for ophthalmic delivery", J. Microencapsul., 28, 37-45 (2011).

20- C. Bucolo, A. Maltese, G. Puglisi and R. Pignatello, "Enhanced ocular antiinflammatory activity of ibuprofen carried by a Eudragit $\mathrm{RS}_{100}{ }^{\circledR}$ nanoparticle suspension", Ophthalmic Res., 34, 319 323 (2002).

21- R. Pignatello, C. Bucolo, G. Spedalieri, A. Maltese and G. Puglisi, "Flurbiprofenloaded acrylate polymer nanosuspensions for ophthalmic application", Biomaterials, 23, 3247-3255 (2002).

22- K. Adibkia, M. R. S. Shadbad, A. Nokhodchi, A. Javadzedeh, M. B. Jalali, J. Barar, G. Mohammadi and Y. Omidi, "Piroxicam nanoparticles for ocular delivery: Physicochemical characterization and implementation in endotoxininduced uveitis", Journal of Drug Targeting, 15 (6), 407-416 (2007).

23- H. Nejat, M. Rabiee, R. Varshochian, M. Tahriri, H. E. Jazayeri, J. Rajadas, H. Ye,
Z. Cui, and L. Tayebi, "Preparation and characterization of cardamom extractloaded gelatin nanoparticles as an effective targeted drug delivery system to treat glioblastoma", Reactive and Functional Polymers, 120, 46-56 (2017).

24- J. Vandervoort and A. Ludwig, "Preparation and evaluation of drugloaded gelatin nanoparticles for topical ophthalmic use", European Journal of Pharmaceutics and Biopharmaceutics, 57, 251-261 (2004).

25- C. A. Peptu, G. Buhus, M. Popa, A. Perichaud and D. Costin, "Double crosslinked chitosan gelatin nanoparticles for ophthalmic applications", J. Bioact. Compat. Pol., 25, 98-116 (2010).

26- R. M. Hathout and M. K. Omran, "Gelatin-based particulate systems in ocular drug delivery", Pharmaceutical Development and Technology, 21 (3), 379-386 (2015).

27- B. Nagavarma, H. K. Yadav, A. Ayaz, L. Vasudha and H. Shivakumar, "Different techniques for preparation of polymeric nanoparticles a review", Asian Journal of Pharmaceutical and Clinical Research, 5 (3), 16-23 (2012).

28- N. Younis, M. A. Shaheen and M. H. Abdallah, "Silymarin-loaded Eudragit ${ }^{\circledR}$ RS100 nanoparticles improved the ability of silymarin to resolve hepatic fibrosis in bile duct ligated rats", Biomedicine \& Pharmacotherapy, 81, 93-103 (2016).

29- A. Mahor, S. K. Prajapati, A. Verma, R. Gupta, A. K. Lyer and P. Kesharwani, "Moxifloxacin loaded gelatin nanoparticles for ocular delivery: Formulation and in-vitro, in-vivo evaluation", Journal of Colloid and Interface Science, 483, 132-138 (2016).

30- A. Parra, M. Mallandrich, B. Clares, M. A. Egea, M. Espina, M. L. Garcia and A. C. Calpena, "Design and elaboration of freeze-dried PLGA nanoparticles for the transcorneal permeation of carprofen: Ocular anti-inflammatory applications", Colloids and Surfaces B: Biointerfaces, 136, 935-943 (2015).

31- Z. M. A. Fathalla, K. A. Khaled, A. K. Hussein, R. G. Alany and A. Vangala, "Formulation and corneal permeation of ketorolac tromethamine-loaded chitosan 
nanoparticles", Drug Development and Industrial Pharmacy, 42 (4), 514-524 (2015).

32- A. Sabzevari, K. Adibkia, H. Hashemi, A. Hedayatfar, N. Mohsenzadeh, F. Atyabi, M. H. Ghahremani and R. Dinarvand, "Polymeric triamcinolone acetonide nanoparticles as a new alternative in the treatment of uveitis: In-vitro and in-vivo studies", European Journal of Pharmaceutics and Biopharmaceutics, 84 (1), 63-71 (2013).

33- Ameeduzzafara, S. S. Imam, S. N. A. Bukhari, J. Ahmed and A. Ali, "Formulation and optimization of levofloxacin loaded chitosan nanoparticles for ocular delivery: In-vitro characterization, ocular tolerance, and antibacterial activity", International Journal of Biological Macromolecules, 108, 650-659 (2018).

34- G. Mohammadi, E. Namadib, A. Mikaeilic, P. Mohammadi and K. Adibkia, "Preparation and physicochemical characterization of the Nystatin-Loaded Eudragit RS 100/PLGA nanoparticles and evaluation of their anti-fungal properties against Candida albicans", Journal of Drug Delivery Science and Technology, 38, 90-96 (2017).

35- M. Barzegar-Jalali, M. Alaei- Beirami, Y. Javadzadeh, G. Mohammadi, A. Hamidi, S. Andalib and K. Adibkia, "Comparison of physicochemical characteristics and drug release of diclofenac sodiumeudragit $^{\circledR}$ RS100 nanoparticles and solid dispersions", Powder Technology, 219, 211-216 (2012).

36- S. Jana, S. Manna, A. K. Nayak, K. K. Sen and S. K. Basu, "Carbopol gel containing chitosan-egg albumin nanoparticles for transdermal aceclofenac delivery", Colloids Surf. B: Biointerfaces, 114, 3644 (2014).

37- J. Malakar, A. K. Nayak and D. Pal, "Development of cloxacillin loaded multiple-unit alginate-based floating system by emulsion-gelation method ", Int. J. Biol. Macro. Mol., 50, 138-147 (2012).

38- S. Jana, N. Maji, A. K. Nayak, K. K. Sen and S.K. Basu, "Development of chitosan-based nanoparticles through inter-polymeric complexation for oral drug delivery", Carbohydr Polymers, 98, 870-876 (2013).

39- T. Gratieri, G. M. Gelfuso, O. de Freitas, E. M. Rocha and R. F. V. Lopeza, "Enhancing and sustaining the topical ocular delivery of fluconazole using chitosan solution and poloxamer/chitosan in situ forming gel", Eur. J. Pharm. Biopharm., 79 (2), 320-327 (2011).

40- C. Canadas, H. Alvarado, A. C. Calpena, A. M. Silva, E. B. Souto, M. L. Garcia and G. Abrego, "In-vitro, ex-vivo and in-vivo characterization of PLGA nanoparticles loading pranoprofen for ocular administration", International Journal of Pharmaceutics, 511 (2), 719-727 (2016).

41- P. Artusson and J. Karlsson, "Correlation between oral drug absorption in humans and apperant drug permeability coefficients in human intestinal epithelial (CACO-2) cells", Biochemical and Biophysical Research Communications, 173 (3) 880-885 (1991)

42- Ameeduzzafar, J. Ali, A. Bhatnagar, N. Kumar and A. Ali, "Chitosan nanoparticles amplify the ocular hypotensive effect of cateolol in rabbits", International Journal of Biological Macromolecules, 65, 479-491 (2014).

43- R. Katara and D.K. Majumdar, "Eudragit RL 100-based nanoparticulate system of aceclofenac for ocular delivery", Colloids and Surfaces B: Biointerfaces, 103, 455462 (2013).

44- R. Alex and R. Bodmeier, "Encapsulation of water-soluble drugs by a modified solvent evaporation method. I. Effect of process and formulation variables on drug entrapment", J. Microencapsul., 7 (3), 347-355 (1990).

45- L. Peltonen, J. Aitta, S. Hyvönen, M. Karjalainen and J. Hirvonen, "Improved entrapment efficiency of hydrophilic drug substance during nanoprecipitation of poly(I) lactide nanoparticles", AAPS Pharm. Sci. Tech., 5, 115-120 (2004).

46- N. Morsi, D. Ghorab, H. Refai and H. Teba, "Ketorolac tromethamine loaded nanodispersion incorporated into thermosensitive in situ gel for prolonged ocular delivery", International Journal of Pharmaceutics, 506 (1-2), 57-67 (2016). 
47- A. Zimmer and J. Kreuter, "Microspheres and nanoparticles used in ocular drug delivery systems", Adv. Drug Deliv. Rev., 16, 61-73 (1995).

48- A. Gandhi, S. Jana and K. K. Sen, "Invitro release of acyclovir loaded Eudragit $\mathrm{RLPO}^{\circledR}$ nanoparticles for sustained drug delivery", International Journal of Biological Macromolecules, 67, 478-482 (2014).

49- J. Ji, S. Hao, D. Wu, R. Huang and Y. Xu, "Preparation, characterization and in-vitro release of chitosan nanoparticles loaded with gentamicin and salicylic acid", Carbohydr. Polym., 85 (4), 803-808 (2011).

50- P. R. Mishra, L. A. Shaal, R. H. Müller and C. M. Keck, "Production and characterization of hesperetin nanosuspensions for dermal delivery", Int. J. Pharm., 371, 182-189 (2009)

51- M. Kamranifara, A. Allahresanib and A. Naghizadehc, "Synthesis and characterizations of a novel $\mathrm{CoFe}_{2} \mathrm{O}_{4} @ \mathrm{CuS}$ magnetic nanocomposite and investigation of its efficiency for photocatalytic degradation of penicillin $G$ antibiotic in simulated waste water", Journal of Hazardous Materials, 366, 545-555 (2019).

52- A. Naghizadeh and M. Ghafouri, "Synthesis and Performance Evaluation of Chitosan Prepared from Persian Gulf Shrimp Shell in Removal of Reactive Blue 29 Dye from Aqueous Solution (Isotherm, Thermodynamic and Kinetic Study)", Iran. J. Chem. Chem. Eng., 36 (3), 25-36 (2017).

53- A. Naghizadeh, H. Shahabi, F. Ghasemi and A. Zarei, "Synthesis walnut shell modified with titanium dioxide and zinc oxide nanoparticles for efficient removal of humic acid from aqueous solutions", Journal of Water and Health, 14 (6), 989-997 (2016).
54- A. Naghizadeh and R. Nabizadeh, "Removal of reactive blue 29 dye by adsorption on modified chitosan in the presence of hydrogen peroxide", Environment Protection Engineering, 42 (1), 149-168 (2016).

55- K. S. Basu, K. Kavitha and M. Rupeshumar, "Evaluation of ketorolac tromethamine microspheres by chitosan/gelatin B complex coacervation", Sci. Pharm., 78 (1), 79-92 (2010).

56- M. Kamranifar and A. Naghizadeh, "Montmorillonite Nanoparticles in Removal of Textile Dyes from Aqueous Solutions: Study of Kinetics and Thermodynamics", Iran. J. Chem. Chem. Eng., 36 (6), 127-137 (2017).

57- J. B. Naik and V. J. Mokale, "Formulation and evaluation of repaglinide nanoparticles as a sustained release carrier", Novel Sci. Int. J. Pharm. Sci., 1, 259-266 (2012).

58- J. V. Aukunuru and U. B. Kompella, "Invitro delivery of nano and microparticles to retinal pigment epithelial (RPE) cells", Drug Del. Technol., 2, 50-57 (2002).

59- F. Rafie, Y. Javadzadeh, A. R. Javadzadeh, L. A. Ghavidel, B. Jafari, M. Moogooee and S. Davaran, "Ocular drug delivery on rabbit eye", Curr. Eye Res., 35, 1081-1089 (2010).

60- J. G. Souza, K. Dias, T. A. Pereira, D. S. Bernardi and R. F. V. Lopez. "Topical delivery of ocular therapeutics: Carrier systems and physical methods", J. Pharm. Pharmacol., 66, 507-530 (2013).

61- A. Martin and P. Bustamante, "Physical Pharmacy, Physical Chemical Principles in the Pharmaceutical Science", $4^{\text {th }}$ Edn. Lea \& Febiger, Philadelphia (1993).

62- A. P. Gadad, P. S. Chandra, P. M. Dandagi and V. S. Mastiholimath, "Moxifloxacin Loaded Polymeric Nanoparticles for Sustained Ocular Drug Delivery", International Journal of Pharmaceutical Sciences and Nanotechnology, July September, 5 (2), 1727-1734 (2012). 
Bull. Pharm. Sci., Assiut University, Vol. 43, Issue 1, 2020, pp. 79-94.

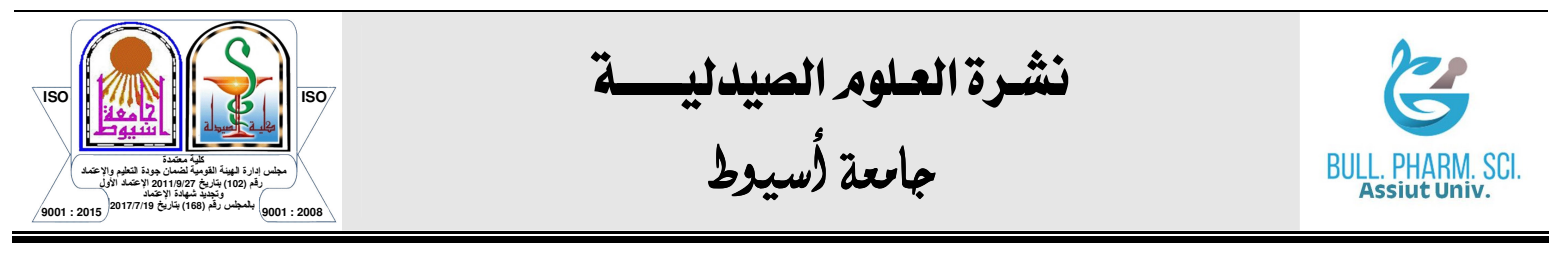

\section{جسيمات متناهية الصغز محملة بالكيتورولاك تروميثامين للتوصيل فى العين:

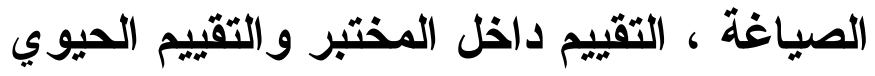

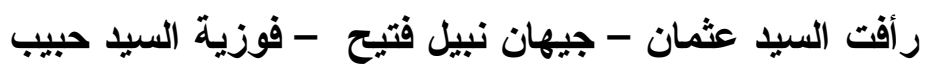 \\ قسم الصيدلانيات ، كلية الصيدلة ، جامعة أسيوط ، أسيوط ، مصر}

كان هدف هذه الدر اسه هو صياغة كيتورو لالك تروميثامين محمل على جسيمات منتاهية الصغر

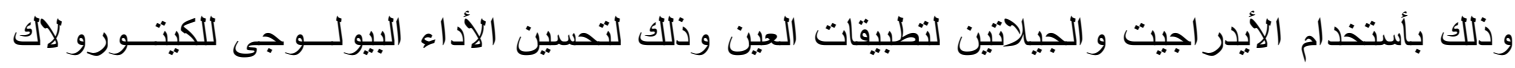

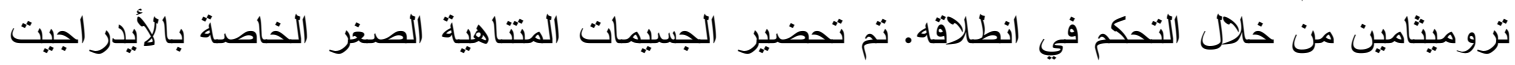

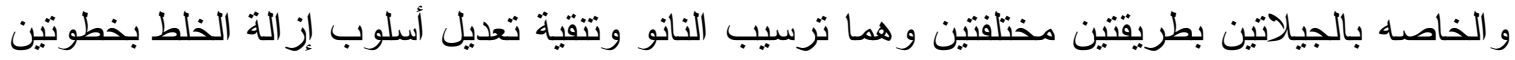

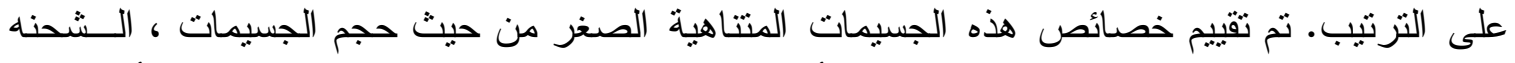

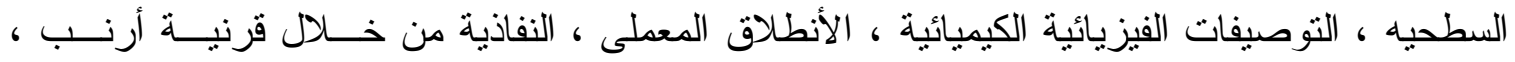

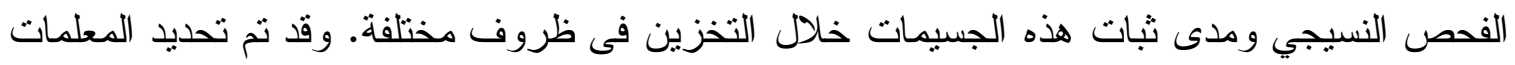

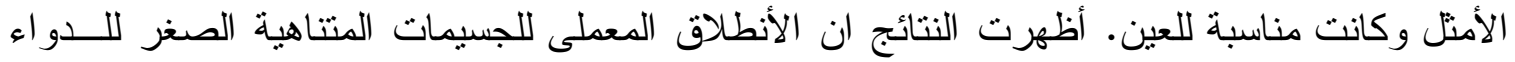

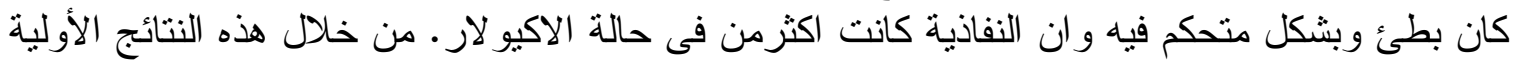

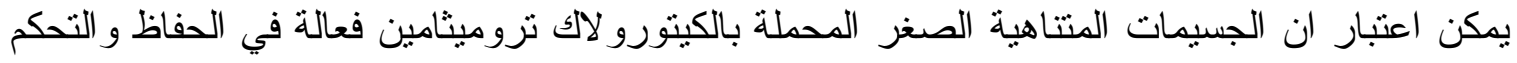
على إنطلاق العقار ويمكن استخدامها لتحسين توصيل العقار للعين. 